D.O.I: $10.3895 / \mathrm{S} 1808-04482013000200004$

\title{
PRODUÇÃO ENXUTA: APLICAÇÃO DA FERRAMENTA MAPA DO FLUXO DE VALOR (MFV) EM UMA INDÚSTRIA DE CALÇADOS FEMININOS
}

\section{LEAN PRODUCTION: APPLICATION OF THE TOOL OF VALUE STREAM MAPPING (VSM) IN AN INDUSTRY OF WOMEN SHOES}

\author{
Célio Favoni ${ }^{1}$; Catarina Barbosa Careta $^{2}$; Marcos Antonio Bonifácio ${ }^{3}$; André Luiz Orselli ${ }^{4}$ \\ ${ }^{1}$ Faculdade de Tecnologia de Jahu - FATEC JAHU - Jaú - Brasil \\ favoni@hotmail.com \\ ${ }^{2}$ Escola de Engenharia de São Carlos, Univ. de São Paulo - EESC/USP - São Carlos - Brasil \\ catarinacaretta@sc.usp.br \\ ${ }^{3}$ Faculdade de Tecnologia de Jahu - FATEC JAHU - Jaú - Brasil \\ calcado@fatecjahu.edu.br \\ ${ }^{4}$ Faculdade de Tecnologia de Jahu - FATEC JAHU - Jaú - Brasil \\ andre_orselli@hotmail.com
}

\begin{abstract}
Resumo
A Produção Enxuta é baseada em esforços para otimizar ou eliminar desperdícios e atividades que não agregam valor (NAV) aos olhos do cliente final, através da aplicação dde ferramentas como: Trabalho Padronizado, Mapa do Fluxo de Valor, TPM, SMED, TQM, Kaizen, Gestão Visual, Nivelamento e balanceamento da Produção e Flexibilização da mão de obra. Considerando que, em um mundo globalizado com as rápidas mudanças tecnológicas e ciclo de vida do produto cada vez menor, as empresas começaram a adotar novas formas de produção onde a fabricação pode definir seu sucesso competitivo. O setor calçadista brasileiro apresenta alto grau de competição, demanda sazonal, curto ciclo de produto e alto mix de produtos. Desta maneira, a aplicação de técnicas que possam contribuir para o aumento da competitividade deste setor se faz necessário. Diante do exposto, o presente artigo visa aplicar da ferramenta Mapa do Fluxo de Valor (MFV) em uma indústria de calçados. A empresa produz exclusivamente sapatos femininos, possui alto mix de produção, ciclo do produto de 2-3 meses e capacidade de produção de 1.100 pares por dia. Os resultados sugerem ganhos de competitividade para a empresa, diagnosticado pela redução do lead time em 40\%, passando dos atuais 33,88 dias para 20,24 após as sugestões de melhoria, além da diminuição dos índices de refugo/retrabalho de $12,72 \%$ para apenas $2 \%$.
\end{abstract}

Palavras-chave: produção enxuta; mapa do fluxo de valor; indústria de calçados.

\section{Introdução}

Competição global, rápidas mudanças tecnológicas e ciclo de vida dos produtos cada vez menor, têm orientado as empresas a adotarem novas maneiras de produção (SHAH e WARD, 2003; DIGALWAR e SANGWAN, 2007), sendo que o grande desafio atual das organizações é fazer a 
manufatura contribuir para o sucesso competitivo das empresas, perpetuando-as de forma sustentável (SLACK, 2009).

A proposta do Lean Production, também conhecida como Produção Enxuta, adotada pelas empresas japonesas a partir dos anos 40, tendo Eiji Toyoda e Taiichi Ohno, da Toyota, como seus mais importantes ícones, propiciou e incluiu novos mecanismos para a excelência de produção e reuniu o melhor dos métodos artesanais e da produção em massa: redução de custos unitários, melhoria da qualidade, mix de produtos e trabalho cada vez mais estimulado (WOMACK et al, 2004).

O despertar destes novos conceitos somente foi mostrado ao resto do mundo no final dos anos 80, quando do lançamento do livro "A máquina que mudou o mundo" de Womack e Jones (1990). Neste livro foram publicados os resultados de uma pesquisa realizada pelo Massachusetts Institute of Technology (MIT) acerca do desempenho superior das empresas automotivas japonesas, mais especificamente da Toyota Motor Company, frente às americanas.

Esse processo de mudança testemunhou a transformação da manufatura tradicional (em massa) para a abordagem toyotista (produção enxuta), obrigando as empresas, principalmente as ocidentais, a buscarem novas maneiras de se manterem competitivas, principalmente flexibilizando a produção. O Sistema Toyota de Produção (STP) foi criado a partir da identificação dos desperdícios pertinentes à produção e da criação de uma série de ferramentas para evitá-los, partindo de técnicas simples de gestão visual que permitem que cada pessoa saiba o deve fazer em diferentes situações (HOLWEG, 2007).

$\mathrm{Na}$ literatura têm-se diagnosticado que a implementação, total ou parcial, das ferramentas da Produção Enxuta (MFV, Trabalho Padronizado, TPM, SMED, TQM, Fluxo Contínuo, Sistemas Puxados, Cadeia de Fornecedores, Kaizen, Gestão Visual, Nivelamento da Produção e Flexibilização da mão de obra), proporciona ganhos de competitividade para as empresas e que tais práticas produzem melhoria de desempenho operacional, em um primeiro momento, e depois esses resultados proporcionam melhoria do desempenho do negócio (SILVA et al, 2010; LIN e CHANG, 2006; KAYNAK, 2003).

Quanto à mentalidade enxuta em empresas calçadista, Yoshino (2008) através da pesquisa com 10 empresas nacionais de diferentes polos, concluiu que poucas delas adotam alguma ferramenta, principalmente pela falta de mão de obra capacitada, cultura organizacional e falta de conhecimento sobre a filosofia.

O segmento calçadista brasileiro observou declínio de sua competitividade nos últimos anos em virtude das mudanças tecnológicas, abertura econômica e principalmente pela concorrência dos países asiáticos. Apesar da maior parte da produção brasileira estar concentrada nas grandes 
companhias, a característica do setor é de pequenas e médias empresas, que entram e saem facilmente do mercado e que ainda possuem ultrapassadas ferramentas de gestão.

Considerando que a produção enxuta continua sendo disseminada no meio empresarial (SAURIN et al, 2010), que as Pequenas e Médias (PMEs) e em especial, as que produzem calçados, ainda utilizam mecanismos de controle e execução da produção ultrapassados e muitas vezes sem foco estratégico (BACHEGA e GODINHO FILHO, 2011), o objetivo deste trabalho foi aplicar a ferramenta Mapeamento do Fluxo de Valor (MFV) em uma indústria de calçados típica do Arranjo Produtivo Local - APL ${ }^{1}$ da cidade de Jaú/SP.

A escolha da ferramenta MFV foi motivada por ser, segundo Lima e Zawislak (2003), uma metodologia em que não há investimentos em equipamentos ou software, sendo o maior custo o processo de "pensar" novas melhorias na produção e no relacionamento com clientes e fornecedores, podendo ser utilizada por qualquer tipo de organização mesmo em um setor carente de práticas de gestão como o de calçados.

Para Ferro (2003), o MFV é uma ferramenta capaz de olhar para os processos que agregam valor horizontalmente, enfatizando as atividades, ações e conexões no sentido de criar valor e fazêlo fluir desde os fornecedores até os clientes finais. Possibilita a identificação de gargalos produtivos, mas principalmente uma maneira de pensar sobre o que poderia ser melhorado, no sentido de reduzir os desperdícios inerentes à produção.

A fim de se cumprirem os objetivos propostos, a estrutura do trabalho é a que segue: na próxima seção foi feito um levantamento bibliográfico sobre Produção Enxuta, Mapeamento do Fluxo de Valor (MFV), Setor Calçadista; na seção 3 é descrita a metodologia; na seção 4 os resultados e discussões e na seção 5 são tecidas algumas considerações finais.

\section{Fundamentação teórica}

\subsection{Produção enxuta}

Diversos estudos têm demonstrado que o sistema de produção introduzido pela Toyota - ou Produção Enxuta, é o sucessor do tradicional modelo de produção em massa fordista, podendo este novo modelo ser aplicado em qualquer organização empresarial (SHAH e WARD, 2003; SHINGO, 1996; PETTERSEN, 2009) e que o crescimento da aplicação desta filosofia nas organizações ocorreu devido à validação de seus resultados, sendo o tema de várias pesquisas (HALLGREN e OLHAGER, 2009; KAYNAK, 2003; FULLERTON e MCWATTERS, 2001; SALGADO et al, 2009).

\footnotetext{
${ }^{1}$ Arranjos Produtivos Locais ou cluster são aglomerações de empresas de pequeno e médio porte capazes de gerar um conjunto de benefícios aos produtores, exercendo um papel importante para o aumento da competitividade (SUZIGAN et al., 2003).
} 
A Toyota chamou atenção mundial pela primeira vez na década de 1980, quando a qualidade e a eficiência dos carros japoneses superaram os produzidos no ocidente, sobretudo porque duravam mais que os carros americanos e exigiam menor manutenção (LIKER, 2005).

A história da Toyota se confunde com a própria história do Japão. Nos anos 1950, o governo japonês acreditava que uma indústria automobilística forte deveria ser de produção elevada, com especialização em diferentes tamanhos de carros e preços competitivos. Em vez disso, a Toyota, a Nissan e outras companhias desafiaram o governo e propuseram serem construtores de carros completos e com variedade de modelos. O principal engenheiro da Toyota e, responsável pela implantação de novas formas de produção, Taiichi Ohno, rapidamente percebeu que utilizar os métodos de Detroit, não poderia ter sucesso. Sabia que utilizar somente os métodos da produção artesanal, não poderia fabricar produtos para atender o mercado e diante disso teve que procurar um novo enfoque de produção (WOMACK et al, 2004).

Por volta de 1940 a companhia comprou poucas prensas americanas para fabricação de automóveis. Devido ao tamanho do mercado, essas prensas tinham que operar com relativa flexibilidade, ou seja, fabricava-se de acordo com a mudança de design do produto. Essa maneira de produzir em pequena escala, obrigou-os a criar trocas rápidas de sua ferramentaria (setup), e assim tornar as máquinas e consequentemente a produção, flexível. No início, a Toyota importou máquinas, mas com a guerra, a empresa solidificou seu sistema produtivo com máquinas e equipamentos próprios e se tornou independente em máquinas “chão de fábrica", reduzindo seu custo em torno de $12 \%$ por unidade manufaturada (HOUNSHELL, 1984). "Eiji Toyoda estava determinado em implementar as técnicas de produção em massa na Toyota, mas a restrição financeira e o pequeno volume do mercado japonês não justificavam o tipo de produção comum na Ford e GM" (HOLWEG, 2007, p. 421).

Ohno recebeu de Eiji Toyoda a tarefa de "igualar-se à Ford em produtividade". Após várias visitas às montadoras americanas, Ohno e seus engenheiros se surpreenderam ao notar que o sistema de produção em massa não havia evoluído muito desde as primeiras visitas. Havia muitas falhas enquanto que os equipamentos estavam produzindo grandes lotes e gerando estoques (YOSHINO, 2008).

Diante da impossibilidade de implantar a filosofia de produção americana, Ohno acreditava na importância do fluxo contínuo de materiais, na padronização dos processos e na eliminação de perdas (desperdícios), diferentemente do que acontecia no Fordismo.

Em 1946, Ohno propôs algumas ferramentas que passariam a ser utilizadas no STP, tais como: nivelamento do volume de produção; Just in Time - JIT (kanban); layout focado no produto; trabalho multifuncional, bem como a padronização do trabalho. Para o nivelamento da demanda criou o Heijunka Box a fim de nivelar a produção na montagem e na manufatura (HOLWEG, 2007). 
A abordagem JIT foi uma contribuição de Kiichiro Toyoda (fundador da Toyota Motor Company), influenciado por uma viagem de estudo às plantas da Ford em Michigan onde conheceu o sistema de supermercado dos Estados Unidos, que recoloca os produtos nas prateleiras assim que os clientes os compram (LIKER, 2005). Dessa visão surgiu o sistema Kanban que somente começou em 1950, através de Taiichi Ohno e originalmente foi chamado de "sistema de supermercado" e adaptado ao processo fabril da Toyota (FUJIMOTO e TIDD, 1984).

Em suma, a Produção Enxuta surgiu como um sistema de manufatura cujo objetivo é otimizar os processos e procedimentos através da redução contínua de desperdícios ${ }^{2}$ ou perdas (em japonês $M u d a$ ), como, por exemplo, excesso de inventário entre as estações de trabalho e tempo de espera elevado.

De acordo com Liker (2005), a Toyota, leia-se Taiichi Ohno, identificou sete grandes tipos de perdas (muda) sem agregação de valor em processos administrativos ou de produção.

a) Superprodução: produção de itens para os quais não existe consumo, o que exige custos de estoques, transporte e excesso de pessoal;

b) Espera (tempo sem trabalho): funcionários que ficam vigiando uma máquina ou esperam pelo próximo passo no processamento;

c) Transporte ou movimentação desnecessária: movimento de estoque em processo por longas distâncias, criação de transportes ineficientes ou movimentação de materiais para dentro ou fora do estoque ou entre processos;

d) Superprocessamento ou processamento incorreto: passos desnecessários para processar peças. Uso de ferramenta de baixa qualidade, causando movimentos desnecessários e produzindo defeitos;

e) Excesso de estoques: excesso de matéria prima, de estoque em processo ou de produtos acabados;

f) Movimento desnecessário: qualquer movimento inútil que os funcionários têm que fazer durante o trabalho;

g) Defeitos: produção de peças defeituosas ou para correção. Retrabalho. Descarte e Inspeção.

O conceito da Produção Enxuta, às vezes referida como Just-in-time, também se refere a outros elementos como: fluxo contínuo de materiais, produção puxada, 5S, poka yokes, trabalho padronizado, controle visual, entre outros, usados para favorecer o lucro a curto, médio e longo prazo e a possibilidade de fazer muito mais, com os mesmos recursos (MACKELPRANG e NAIR, 2010; PETTERSEN, 2009).

\footnotetext{
${ }^{2}$ Para Womack e Jones (2004), desperdício é: “qualquer atividade humana que absorve recursos, mas não cria valor”.
} 
Dentro da filosofia do sistema de produção japonês, um dos principais elementos do STP é o kaizen, isto é, uma abordagem de melhoria contínua para eliminar desperdícios, sendo que o princípio é melhorar o trabalho em toda a sua organização, focar nas operações que não agregam valor (NAV) e eliminar desperdícios que geram custos e não valoriza o produto ou serviço (YOSHINO, 2008).

\subsection{Mapeamento do fluxo de valor - MFV}

Para identificar desperdícios, uma ferramenta indispensável é o Mapeamento do Fluxo de Valor - MFV (Value Stream Mapping - VSM), em que se pode visualizar os processos produtivos, representado por fluxo de materiais e informações (ROTHER e SHOOK, 2003; RENTES et al, 2003), sendo uma das maneiras de entrada para a implantação do pensamento enxuto na produção (LIMA e ZAWISLAK, 2003).

O MFV é uma ferramenta qualitativa usada para descrever em detalhes como sua produção opera - Mapa do estado atual - e como deveria operar para criar um fluxo de valor otimizado - Mapa do estado futuro (RENTES et al, 2003) e traduz a filosofia enxuta através dos fluxos de materiais e informações das empresas, proporcionando a visualização da produção e possibilitando identificar os possíveis desperdícios no processo (LIMA e ZAWISLAK, 2003).

Visualmente o MFV é representado na Figura 1, onde são exemplificados e identificados dados de demanda, fluxo de informações dos clientes, planejamento e controle da produção, informação para os fornecedores, os fornecedores, caixas de processos (tempo de ciclo, setup, mão-

de-obra, turnos, etc), inventários (quantidade e localização), valor agregado, lead time e desperdícios. 


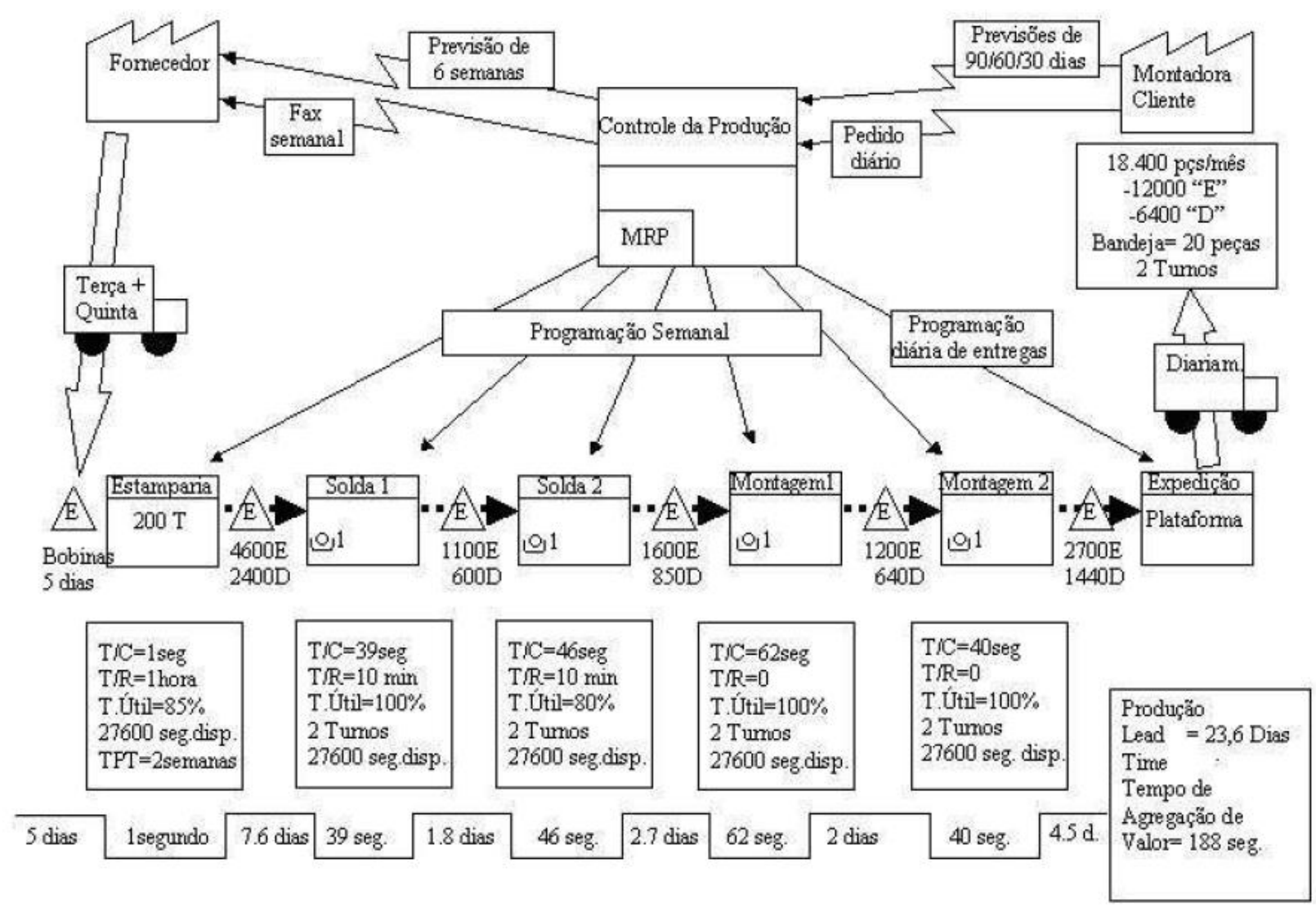

Fonte: ROTHER e SHOOK (2003)

O mapa representa visualmente o fluxo de valor de uma empresa, com informações sobre a demanda do cliente, passando por todas as operações de uma determinada família de produto, inclusive com o número de pessoas envolvidas e a forma como os dados fluem na empresa, desenhando o mapa do estado atual. As propostas de melhorias, por exemplo, na produção, no controle do estoque e do produto final, constituem o mapa do estado futuro. Rother e Shook (2003, p.4) define o Mapeamento do Fluxo de Valor como "uma ferramenta que utiliza papel e lápis e o ajuda a enxergar e entender o fluxo de material e de informação na medida em que o produto segue o fluxo de valor".

\subsection{O setor calçadista}

O setor calçadista brasileiro é formado aproximadamente por 7,9 mil empresas que geram 303 mil empregos diretos, apresenta capacidade instalada em 804 milhões de pares por ano, sendo que 166 milhões foram destinados à exportação em 2008 (ABICALÇADOS, 2011).

Mesmo tendo o estado do Rio Grande do Sul a maior concentração de empresas, considerado o berço do calçado no Brasil, a produção brasileira está gradualmente sendo distribuída 
para outros polos, como o interior do estado de São Paulo (Jaú, Franca e Birigui), bem como em estados emergentes como Paraíba, Ceará, Bahia e Santa Catarina (região de São João Batista).

O polo calçadista de Jaú/SP é formalmente reconhecido como um APL pelos órgãos governamentais e possui aproximadamente 250 empresas fabricantes de calçados, representa mais de $40 \%$ do PIB da cidade e é responsável por 10.000 empregos (dos quais 6.000 diretos e 4.000 indiretos), e possui capacidade instalada para produzir mais de 100.000 pares de calçados/dia, sendo basicamente calçados femininos, na sua grande maioria de couro (SINDICALÇADOS, 2011).

Quanto às etapas envolvidas no processo produtivo de calçados, elas são comuns em qualquer empresa calçadista: corte, pré-pesponto, pesponto, pré-montagem, montagem e acabamento. Basicamente todo calçado passa por estes processos, variando o tempo em cada etapa, layout das máquinas e processo.

a) Corte: responsável pelo corte da matéria-prima que formará o cabedal (parte superior do calçado) e o solado. O corte pode ser manual, utilizando facas e moldes de cartolina, através de uma prensa hidráulica, chamada de balancim de corte, ou pelo processo de CAD/CAM, em que um computador é acoplado a um equipamento de corte a laser, jato de água ou com micro serras;

b) Pesponto: nesta etapa, as partes do cabedal são unidas pela costura com ajuda das máquinas. Esta atividade é segmentada por operações pré-pesponto de acordo com as características do calçado (chanfração, picotagem, dobra e colagem);

c) Pré-montagem: as são a fabricação de solas, saltos e demais peças que comporão o calçado. O solado é produzido paralelamente ao corte e a costura do cabedal, pois envolve o manuseio de vários tipos de materiais como: resinas, borrachas, plásticos, madeira e couro (FENSTERSEIFER, 1995);

d) Montagem: processo no qual os componentes passam a ter a forma de calçado. $\mathrm{O}$ cabedal é montado em uma forma plástica que tem a forma de um pé. Esta etapa envolve outras atividades específicas como: preparação da palmilha, montagem do bico (principalmente o feminino), fechamento do calçados e montagem da traseira (YOSHINO, 2008).

e) Acabamento: envolve as operações de escovação, limpeza, eliminação de excesso de produtos e embalagem do calçado.

\section{Procedimento de pesquisa}

A literatura apresenta diversas estratégias para realização de uma pesquisa, cada uma trazendo diferentes enfoques para a coleta e análise dos dados, sendo que a diferença da estratégia a ser utilizada está relacionada à questão de pesquisa proposta, ao controle que o pesquisador tem sobre eventos comportamentais atuais e ao grau de enfoque em acontecimentos contemporâneos em oposição a acontecimentos históricos (YIN, 2005). 
Segundo Yin (2005), um estudo de caso tem o propósito de obter uma compreensão dos valores e práticas compartilhados por um determinado grupo, utilizando ferramentas e métodos múltiplos para a coleta de dados. Além disso, eles permitem investigações exploratórias onde as variáveis são ainda desconhecidas e o fenômeno ainda não é totalmente compreendido. Dessa forma, esse método de pesquisa foi selecionado por ser considerado o mais adequado para o desenvolvimento desse trabalho.

Com base nas recomendações de Yin (2005), o desenvolvimento da presente pesquisa compreendeu as fases de fundamentação teórica, seleção dos casos, coleta e análise de dados.

A fundamentação teórica, obtida por meio da revisão bibliográfica, possibilitou a identificação da ferramenta da Produção Enxuta passível de ser aplicado na empresa selecionada, além de permitir a busca de experiências ou estudos realizados anteriormente.

Para o estudo de caso foi selecionado uma empresa do APL calçadista de Jaú/SP, com vinte e três anos de atividades, alto mix de produção, ciclo do produto de 2 a 3 meses e com capacidade produtiva de 1100 pares/dia. Seu público alvo são mulheres das classes B e C (classe média brasileira), e seus produtos são confeccionados em couro e distribuídos no mercado interno, em especial São Paulo (95\%).

Os dados foram obtidos junto ao encarregado pelo PCP que possui conhecimento sobre produção enxuta, adquirido em palestras em faculdades e pelo sindicato das empresas, com destaque as abordagens 5S, melhoria do arranjo físico, TPM, Gestão Visual, SMED e padronização do trabalho.

A análise de dados consistiu na definição da família de produtos, cálculo do takt time, na descrição das etapas de produção e nos pontos de destaques obtidos na elaboração do Mapa de Fluxo de Valor.

\section{Resultados e discussões}

Apesar da empresa utilizar uma série de ferramentas de apoio à produção, o modelo atual é basicamente o sistema de produção em massa, com muito estoque de produtos em processo e quebra de sequenciamento de lotes de produção.

O planejamento da empresa é realizado pelo departamento de PCP (planejamento e controle de produção), que através de software ERP elabora as ordens de produção, dispara os pedidos de compra de matéria-prima e encaminha o planejamento para o gerente da fábrica.

Para realização da produção no chão de fábrica, o processo é caracterizado pela emissão de pedidos de produção "em lotes" que percorrem os processos e que descrevem o pedido do cliente, a numeração, cores e modelos. 
Toda a produção é empurrada de uma etapa para outro, não existindo controle sobre em que estágio do processo fabril se encontra os pedidos, além do volume de material em processo (WIPWork in Process), resultando em um alto lead time. Acrescenta-se a isto, a política de não parar a produção para corrigir desvios de programação, impactando na concentração de pedidos "quase prontos", porém, com algum tipo de problema no final da linha.

Outro fator que prejudica a produção são os fornecedores de matéria-prima (metais e aviamentos) que apesar de estarem no mesmo município e fazerem entregas diárias de produtos, não conseguem obedecer ao sequenciamento pré-estabelecido para o atendimento dos pedidos de produção.

Os equipamentos são dedicados a cada processo de fabricação do calçados, não sendo utilizados nas demais etapas, e sua manutenção é realizada periodicamente, conforme estabelecido pelo fornecedor do equipamento.

Os tipos de desperdícios mais comuns são a formação de estoque em processo, espera na linha de produção, retrabalho e formação de estoques de produto acabado, em que o produto fica na expedição esperando que todo o lote seja produzido. Neste último caso, as causas são normalmente falta de itens de produção (normalmente enfeites), retrabalho ou falha na programação.

\subsection{Mapa do fluxo de valor do estado atual}

O mapeamento do estado atual representou o fluxo de informações e de materiais, segundo a metodologia de mapeamento proposta por Rother e Shook (2003). Seguindo esta metodologia, o mapeamento do estado atual deve ser fiel aos acontecimentos da empresa, demonstrar seus níveis de estoque, sequenciamento de processos, fluxo de informações e de materiais, propiciando assim uma visão geral do estado da empresa.

Para a elaboração do MFV, inicialmente se definiu a família de produtos, levando-se em consideração o volume de vendas entre os meses de novembro e dezembro de 2010. Foi constatado que neste período existiram 168 produtos diferentes sendo produzidos, dos quais aproximadamente $85 \%$ possuíram o mesmo macro sequenciamento de processos, sendo a única diferença variações em quantidades de peças e tempos de processamentos. Para Rother e Shook (2003), quando o mix de produto é muito complexo, pode ser criada uma matriz de processos e equipamentos em um eixo e de produtos no outro eixo, ficando mais fácil identificar uma família de produtos.

Para estabelecer o fluxo da família de produtos, foi cronometrado um modelo em todas as operações durante o processo produtivo. A partir desta cronometragem foi possível identificar as operações que agregam (AV) ou não agregam valor (NAV) ao produto, do ponto de vista do cliente final. Algumas operações destacadas, embora não pareçam no primeiro momento agregação de valor, foram baseadas em devoluções ou reclamação de clientes. Foram listados 123 processos 
sendo que apenas $24,4 \%$ ou 30 deles, são perceptíveis aos olhos dos clientes. Nas demais operações estão oportunidades de melhoria, que não impactam no aspecto do produto final, mas tem grande peso sobre o custo final.

Para elaboração do MFV atual, estimou-se um takt time de 28,8s, ou seja, a cada 28,8 segundos, um par de sapatos foi vendido, com base na produção médio-diária de 1.100 pares, fabricados em somente 1 turno. Logo após, cronometrou-se os tempos de ciclo (T/C) de cada etapa do processo de fabricação (Figura 2).

As matérias primas são recebidas semanalmente, exceto metais, com estocagem média de 5 dias para sola, salto, palmilha e tecido sintético. Já o couro, principal matéria prima, tem estoque médio de 12 dias, tendo em vista a distância do fornecedor e o alto tempo de reposição de estoque. Como não há um programa de classificação ou formalização de parceria com fornecedores e para evitar renegociação de prazos com clientes, a alternativa normalmente é acumular estoques de matérias primas.

Figura 2 - Mapa do fluxo de valor - estado atual

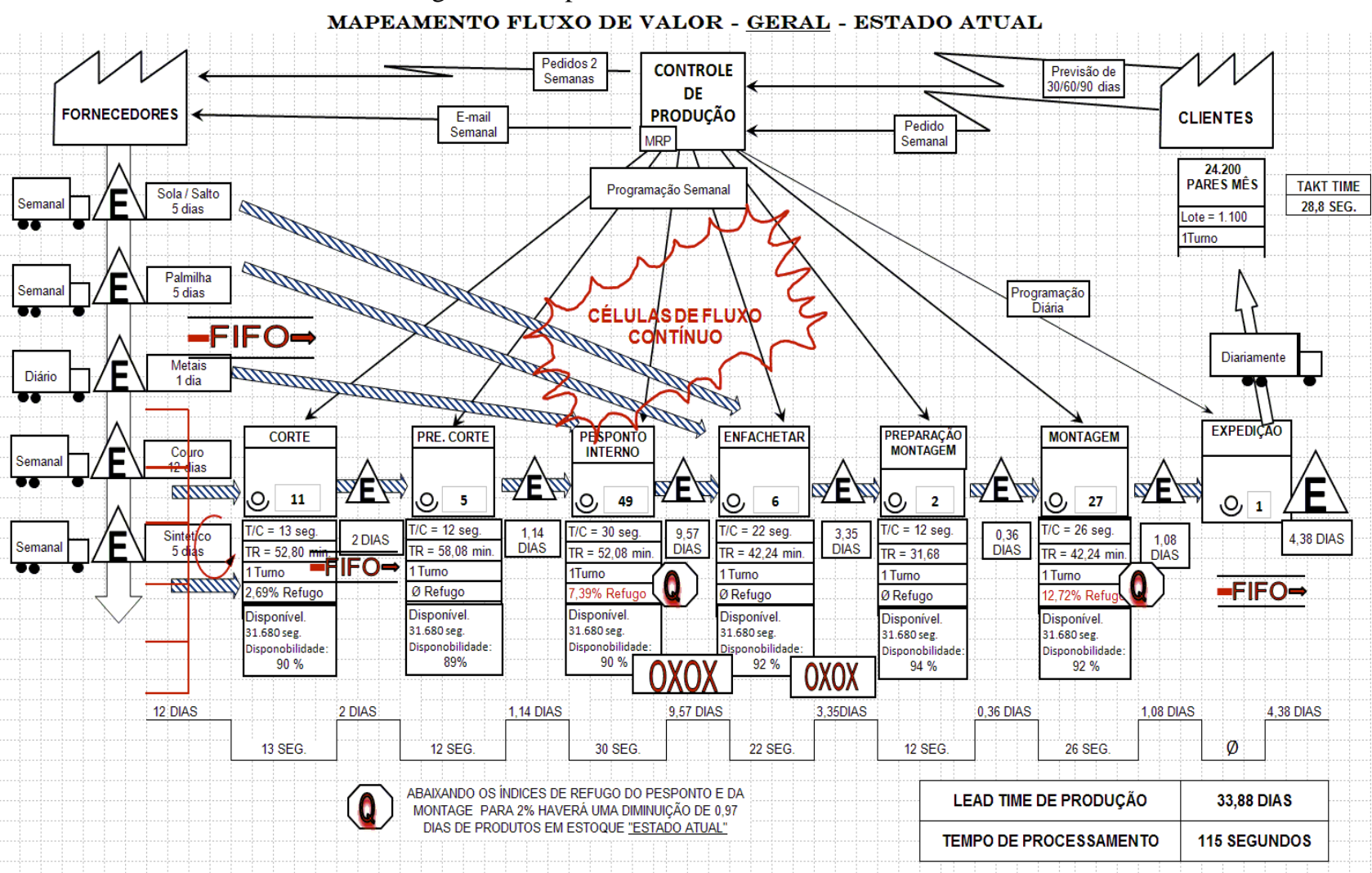

Fonte: Pesquisa de campo (2010)

A empresa recebe os pedidos firmes dos clientes através de ordens (Make to order - MTO) e o comercial envia os pedidos ao PCP, que emite as ordens de compra aos fornecedores e dispara a ordem de produção. As ordens de produção são recebidas pelo gerente que encaminha ao almoxarifado, que separa as matérias primas e empurra para a etapa de corte. 


\subsubsection{Corte}

Apesar do maior investimento da empresa ter ocorrido na compra de uma máquina de corte computadorizada (CAD/CAM), o que reduziu significativamente o tempo de ciclo desta etapa, ainda assim identificou-se uma das causas do não sequenciamento dos lotes, pois como a matéria prima é enviada pelo almoxarifado com um dia de antecedência, o operador do corte seleciona as fichas de produção de maneira que lhe for mais cômoda, sem se importar com o sequenciamento definido pelo PCP.

O tempo de ciclo $(\mathrm{T} / \mathrm{C}=13 \mathrm{~s})$ é menor que o takt time $(28,8 \mathrm{~s})$, mas a saída de material cortado não obedece exatamente o planejado, e algumas ordens são deixadas de lado em beneficio de outras, impossibilitando o fechamento de lotes e de pedidos logo no início do processo.

\subsubsection{Pesponto}

O pesponto é considerado a etapa gargalo do processo de produção de calçado $(\mathrm{T} / \mathrm{C}=30 \mathrm{~s})$, pois envolve a costura de todas as partes que compõem o cabedal (couro, fivela, enfeites, etc) e além do mais, necessita de grande quantidade de mão de obra especializada (49 operadores), pois cabe ao pespontador ter habilidades em unir as peças e conhecer o procedimento de costura de mais de 168 tipos de calçados produzidos durante o período de estudo.

Para diminuir o tempo de ciclo, a empresa terceiriza parte desta atividade (30\%), que são confeccionados por bancas ou ateliês ${ }^{3}$. Mesmo assim, há um grande volume de material que fica “esperando" terminar todo o lote de produção e só então ser empurrado para o processo seguinte, incorrendo um estoque de material estimado de 9,57dias.

Apesar de possuir um layout que deveria seguir um fluxo linear, é possível detectar que as fichas de produção se deslocam muito e com vários cruzamentos de processos (Figura 3).

Figura 3 - Layout atual e "caminho" do calçado no pesponto

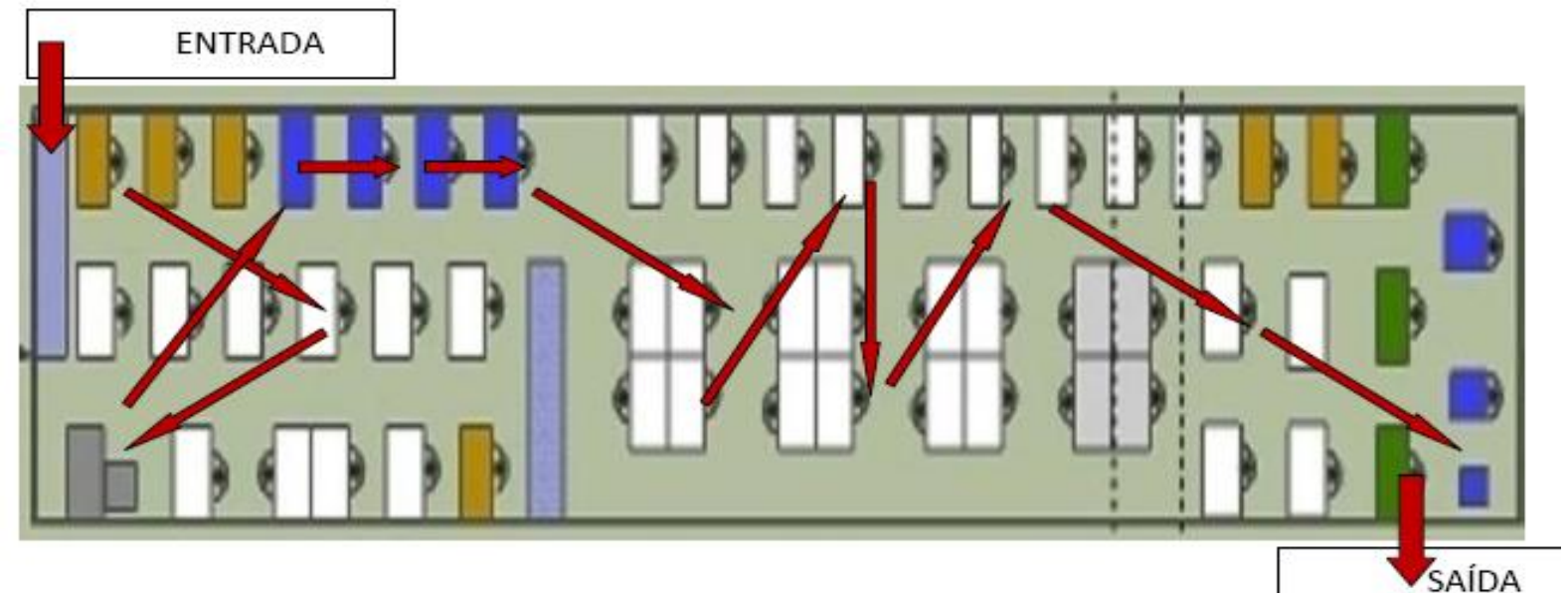

Fonte: Pesquisa de campo (2010)

\footnotetext{
${ }^{3}$ Bancas, ateliês ou facções são expressões para definir, na indústria calçadista, o prestador de serviços que realiza algumas etapas da fabricação, especialmente a costura das partes do calçado.
} 
O problema com o controle da qualidade dentro do Pesponto é outro fator altamente relevante, tendo em vista que não existe uma metodologia de trabalho favorável à resolução dos problemas, tratando-os de modo que não tornem a ocorrer novamente. Possui muito produto em estoque, alto índice de refugos e desorganização das informações sobre o andamento da produção. Outro fator relevante são os frequentes atrasos de pedidos dos fornecedores de metais e aviamentos, que apesar de fazerem entregas frequentes, não seguem o sequenciamento correto.

Uma questão que chama a atenção é o desperdício (7,39\%), pois existe um alto índice de refugo de produtos que aparecem ao longo da fabricação, porém sempre no final de cada etapa.

\subsubsection{Pré-montagem e montagem}

Os processos de enfachetar e preparação são etapas consideradas pré-montagem, pois são realizadas atividades de colagem da palmilha, colocação de cabedal na fôrma e chanfração, que é a retirada de excesso de material nas bordas do cabedal para melhorar a união de uma peça à outra. Mesmo possuindo um tempo de ciclo menor que o takt time, esses processos colaboram para o aumento do lead time final do produto, pois possuem estoques em processo (WIP) de quase 04 dias de produção.

A montagem é responsável pela união de todas as partes do calçado. Para facilitar o processo, os componentes dos calçados seguem em uma esteira giratória, que os empurra para cada operador que fica fixo em posições predeterminadas na esteira. Em cada posição é realizada uma atividade: aquecer a cola no solado e cabedal, montar a parte traseira e no caso do calçado feminino, montar o bico fino, característico deste produto.

O T/C é bem próximo ao takt (26s), entretanto possui alto volume de refugo e retrabalho $(12,72 \%)$, em virtude da política de não parar a produção para corrigir desvios de programação, impactando na concentração de fichas "quase prontas", porém, com algum tipo de problema no final da linha de produção.

O maior problema desta etapa é o abastecimento e o não nivelamento da produção, proporcionando um grande número de pedidos que não podem ser terminados por estarem incompletos, acarretando em estoques de pedidos inacabados ao final da montagem de praticamente 1 dia.

Após a montagem, o calçado vai para a expedição onde fica esperando cerca de 4,38 dias a produção de todo o pedido do cliente.

O resultado final de todo este processo é um lead time de produção de 33,88 dias, mas com tempo de agregação de valor de apenas $115 \mathrm{~s}$, ou seja, o calçado precisa apenas de 2 minutos para a sua fabricação, mas fica parado esperando o término de todo o pedido quase 34 dias. 


\subsection{Mapa do fluxo de valor do estado futuro}

Com o mapeamento do estado atual, algumas propostas de melhorias foram sugeridas, e podem ser implementadas. Para que estas mudanças ocorram, é recomendável que exista um responsável pelo do fluxo de valor, para garantir a efetivação das mudanças, e também instruir eventuais dúvidas sobre as mesmas. Rother e Shook, (2003), definem esta pessoa como o "gerente do fluxo de valor" e sugerem que ela se reporte à pessoa com maior autoridade na unidade produtiva, tendo assim o poder necessário para fazer as mudanças acontecerem.

O mapeamanto do estado futuro é a expresão do que seria ideal para a família de produtos mapeada, com propostas de mudanças realizadas.

No Mapa do Estado Futuro procurou-se demonstrar como a produção da empresa poderá ser realizada caso as propostas de melhoria e a aplicação de outras ferramentas (Nivelamento da Produção, Kanban, Gestão Visual e Flexibilização da Mão de Obra) forem implementadas, além do envolvimento da diretoria e gerência (Figura 4).

Figura 4 - Mapa do fluxo de valor - estado futuro

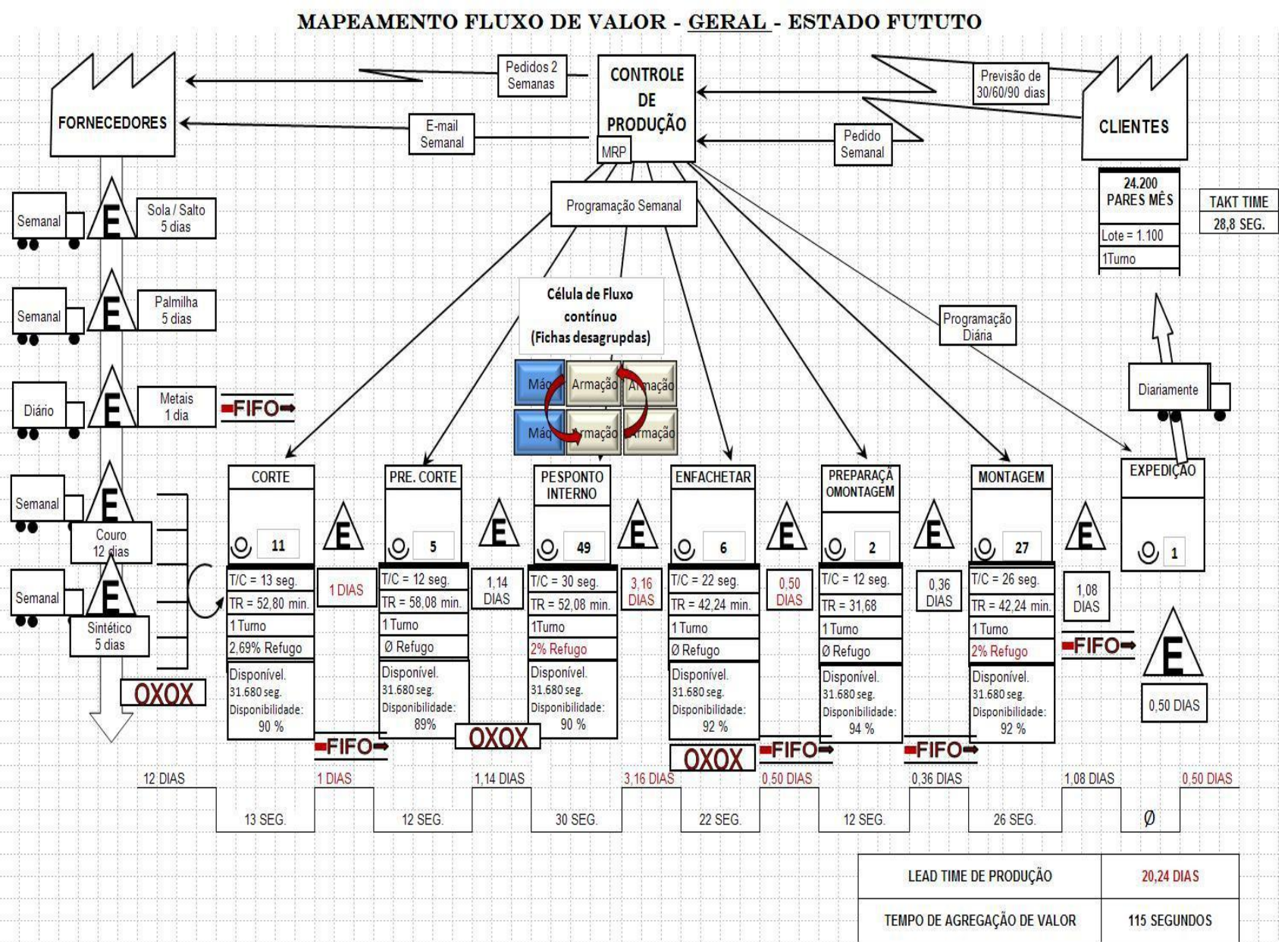

Fonte: Pesquisa de campo (2010) 


\subsubsection{Corte}

As melhorias propostas foram a criação de um supermercado no almoxarifado para abastecimento e a nivelação da produção "Heijunka Box", com o intuito de diminuir o tempo de espera das fichas de produção, que podem ser reduzidas de dois para apenas um dia.

$\mathrm{Na}$ preparação do corte, o maior cuidado é para que não fiquem fichas paradas por muito tempo, e possam seguir o mesmo ritmo e sequenciamento de produção estabelecido para o corte, trabalhando com baixo nível de estoque em processo.

A alternativa é a diminuição dos lotes de produção e estoques, e produzir as ordens na medida em que são necessárias para atender aos pedidos. $\mathrm{O}$ resultado esperado será o aumento no giro da produção.

\subsubsection{Pesponto}

Esta etapa é a que sofreria maiores mudanças, pois além de seguir o mesmo método de trabalho do corte, "produzindo primeiro o que chega primeiro", também poderia receber um supermercado para garantir que a produção seja puxada conforme a necessidade dos pedidos. O nivelamento da produção também se faz necessário devido a fatores externos, como o de aviamentos e metais, que embora realizem entregas todos os dias, nem sempre segue a programação estabelecida e combinada. O fato é que, caso exista a necessidade de adiantar ou arrasar algum pedido, o mesmo será controlado e não realizado aleatoriamente como se faz no mapeamento do estado atual, deixando que as fichas fossem estocadas ao lado dos operadores, desta forma alterando o layout anterior.

O pesponto é também penalizado com a filosofia do "toca pra frente" e possui um alto índice de refugos. Este problema pode ser minimizado dando maior autonomia para os operadores, para que possam exigir maior qualidade do processo anterior, e não enviar produtos defeituosos para a próxima etapa.

\footnotetext{
4 Toca pra frente: expressão conhecida no meio calçadista que significa passar por cima ou ignorar pequenos problemas, para que a produção não fique parada. Esta filosofia segundo Womack et al, (2004) também é encontrada em empresas de produção em massa do setor automobilístico.
} 
Figura 5 - Layout proposto para o pesponto

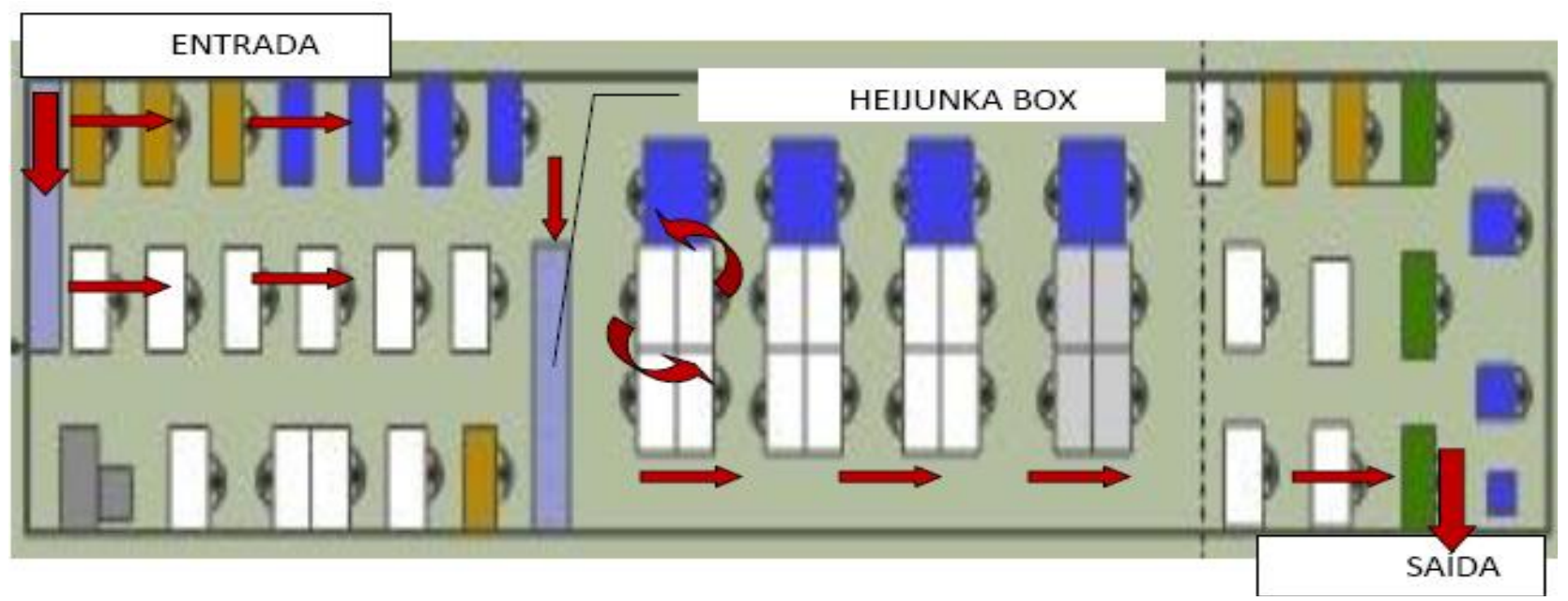

Fonte: Pesquisa de campo (2010)

A criação de células de fluxo contínuo é sem dúvida onde as mudanças poderão ser mais impactantes (Figura 5), sendo o fluxo de produção mais organizado. Quando operavam separadamente, havia grandes volumes de produtos em processo (9,57 dias), mas com a criação de células de fluxo contínuo, com o nivelamento da produção e a criação de um supermercado de abastecimento, toda ficha de produção que chegar à célula será passível de conclusão no mesmo dia, impactando em maior giro da produção e redução do estoque em processo.

\subsubsection{Montagem}

Na pré-montagem (enfachetamento e preparação), sugere-se a criação de um supermercado e a implantação de um sistema FIFO (first in, first out). O resultado será garantir o sequenciamento correto da produção, com redução imediata do estoque do enfachemento de 3,35 dias para apenas 0,50 .

Para a montagem, com melhor sequenciamento e redução de estoques, o ganho esperado será a expressiva queda da taxa de refugo/retrabalho de $12,72 \%$ para $2 \%$, o que eliminaria praticamente um dia de trabalho, e geraria um ganho adicional de 1.067 pares para a empresa.

Em suma, a aplicação das sugestões propostas no MFV futuro, geraria um ganho de competitividade, com redução do lead time de entrega de produto acabado em $40 \%$, diminuindo dos atuais 33,88 para 20,24 dias de espera do cliente.

\section{Considerações finais}

O objetivo deste estudo foi aplicar a ferramenta Mapa de Fluxo de Valor - MFV em uma indústria de calçados do polo calçadista de Jaú/SP, procurando pontos de melhoria nos processos, visando à eliminação ou redução de desperdícios na produção. 
O estudo identificou alguns gargalos no processo produtivo, com destaque ao retrabalho, desperdício de matérias primas e alto tempo de ciclo do produto, além de acúmulo de estoques e sistema empurrado de produção.

A aplicação do MFV sugeriu que a implementação de controles e de melhorias deverá adicionar competitividade à empresa, principalmente com aumento da capacidade de produção instalada e redução de lead time, diminuição dos índices de retrabalho, refugo e devoluções e redução de prazo de entrega aos clientes, proporcionalmente um diferencial em relação à concorrência.

Os resultados demonstraram que a empresa estudada dispõe de pouco conhecimento sobre os conceitos e ferramentas da Produção Enxuta, e ainda desconhece os benefícios que a aplicação destes pode proporcionar.

Apesar de poucos os estudos, a implantação desta filosofia nas indústrias calçadista deve ser o caminho a ser seguido pelos gestores. Durante o mapeamento do fluxo de valor, seja ele atual ou futuro, é fundamental "enxergar" as atividades ou processos que são passíveis de melhoria.

Por fim, destaca-se a contribuição deste trabalho no sentido de que são discutidas as formas de gestão de produção para as Pequenas e Médias Empresas (PMEs), pois àquelas que desejam implantar alguns destes conceitos, deverão adaptar-se as novas exigências do mercado globalizado.

Como propostas futuras, sugere-se a realização de mais estudos que possam colocar em prática as sugestões propostas neste trabalho, e que também possam proporcionar mudanças na cultura empresarial do setor, que ainda se vale de práticas de gestão que focam basicamente os resultados de curto prazo.

\begin{abstract}
Lean production has been applied by organizations around the world as part of strategy to reduce waste in their value stream intending to improve performance. It's based on efforts to optimize or eliminate waste and activities that do not add value (NAV) in the eyes of the end customer through the application of the tools: Standard Work, Value Stream Map, TPM, SMED, TQM, Kaizen, Visual Management, leveling and balancing the production and easing of labor. The Brazilian footwear industry has a high degree of competition, seasonal demand, short product cycle and high product mix. This paper aims to study the opportunities of Value Stream Mapping (VSM) applicability in shoe industry. The industry produces shoes exclusively for women, has high production mix, the product cycle of 2-3 months and production capacity of 1,100 pairs per day. The study confirms that there are several gains in competitiveness for the company, as determined by reducing the production lead time by $40 \%$ from the current 33.88 days to 20.24 days after the suggestions for improvement, in addition to lowering the levels of scrap / rework of $12.72 \%$ to $2 \%$.
\end{abstract}

Key-words: lean production; value stream mapping; shoes industry. 


\section{Referências}

ASSOCIAÇÃO BRASILEIRA DAS INDÚSTRIAS DE CALÇADOS - ABICALÇADOS. Resenha Estatística. Disponível em: www.abicalcados.com.br. Acesso em 07 fev. 2011.

BACHEGA, S. J.; GODINHO FILHO, M. Identificação de foco estratégico e de consistências entre fins e meios em empresas calçadista do Estado de São Paulo. Gestão e Produção, São Carlos, v. 18, n. 2, p. 391-408, 2011.

DIGALWAR, A. K..; SANGWAN, K. S. Development and validation of performance measures for world class manufacturing practices in India. Journal of Advanced Manufacturing Systems, v. 6, n. 1, 21-38, 2007.

cross ref

FENSTERSEIFER, J. E. O Complexo Calçadista em Perspectiva: Tecnologia e Competitividade. Estudos sobre a competitividade da indústria calçadista sob a ótica da tecnologia. Ortiz, 1995.

FERRO, J. R. A essência da ferramenta “Mapeamento do Fluxo de Valor”. Lean Institute Brasil. 2003. Disponível em: http://www.lean.org.br.

FUJIMOTO, T.; TIDD, J. The UK \& Japanese automobile industries: adoption \& adaptation of Fordism. University of Tokio, Japan, 1984.

FULLERTON, R. R.; MCWATTERS, C. S. The production performance benefits from JIT implementation. Journal of Operations Management. v. 19, p. 81-86, 2001.

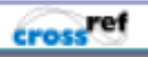

HALLGREN, M.; OLHAGER, J. Lean and agile manufacturing: external and internal drivers and performance outcomes. International Journal of Operations \& Production Management, v. 29, n. 10, p. 976-999, 2009.

\section{cross ref}

HOLWEG, M. The genealogy of lean production. Journal of Operations Management, v. 25, 420-437, 2007.

\section{cross ref}

HOUNSHELL, D.A. From the American System to Mass Production 1800-1932: The Development of Manufacturing Technology in the U.S. Johns Hopkins University Press, Baltimore, 1984.

KAYNAK, H. The relationship between total quality management practices and their effects on firm performance. Journal of Operations Management. V. 21, p. 405-435, 2003.

cross ref

LIN, C; CHANG, S. Exploring TQM's impact on the causal linkage between manufacturing objective and organizational performance. Total Quality Management, v. 17, n. 4, p. 465-484, 2006.

cross ref

LIKER, J. K. O Modelo Toyota: Os 14 princípios de Gestão da maior Fabricante do Mundo. Porto Alegre: Bookman, 2005.

LIMA, M. L. S. C.; ZAWISLAK, P. A. (2003). A produção enxuta como fator diferencial na capacidade de fornecimento de PMEs. Produção. v. 13, n. 2, p. 57-69.

\section{cross ref}

MACKELPRANG, A. W.; NAIR, A. Relationship between just-in-time manufacturing practices and performance: A meta-analytic investigation. Journal of Operations Management, v. 28, 283-302, 2010.

\section{cross ref}

PETTERSEN, J. Defining lean production: some conceptual and practical issues. The TQM Journal. v. 21, n. 2, p. 127-142, 2009. 
RENTES, A. F.; SILVA, A. L.; SILVA, V. C.; CASTRO, S. A. Aplicando os conceitos de lean production em uma indústria de calçados: um estudo de caso. In: SIMPÓSIO NACIONAL DE ENGENHARIA DA PRODUÇÃO SIMPEP, 10, 2003, Bauru. Anais... Bauru: UNESP, 2003.

ROTHER, M.; SHOOK, J. Aprendendo a Enxergar: mapeando o fluxo de valor para agregar valor e eliminar desperdício. Lean Enterprise Institute do Brasil, 2003.

SAlGADO, E. G.; MEllo, C. H. P.; SIlVA, C. E. S.; OlIVEIRA, E. S.; ALMEIDA, D. A. (2009). Análise da aplicação do mapeamento do fluxo de valor na identificação de desperdícios do processo de desenvolvimento de produtos. Gestão \& Produção, v. 16, n. 3, p. 344-356.

cross ref

SAURIN, T. A.; RIBEIRO, J. L. D.; MARODIN, G. A. (2010). Identificação de oportunidades de pesquisa a partir de um levantamento da implantação da produção enxuta em empresas do Brasil e do exterior. Gestão \& Produção, v. 17, n. 4 , p. $829-841$.

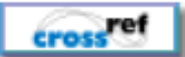

SHAH, R.; WARD, P. Lean manufacturing: context, practice bundles, and performance. Journal of Operations Management, v. 21, 129-149, 2003.

cross ref

SHINGO, S. O Sistema Toyota de produção do ponto de vista da Engenharia de produção. $2^{\mathrm{a}}$ ed. Porto Alegre: Artes Médicas, 1996.

SILVA, E. M.; SANTOS, F. C. A.; CASTRO, M. (2010). Os efeitos diretos e indiretos das práticas de produção sobre o desempenho: Survey em firmas moveleiras no Brasil. RAE-eletrônica, v. 09, n. 2.

cross ref

SINDICALÇADOS DE JAÚ. Caracterização do APL de Calçados Femininos de Jaú. APL. Disponível em: www.sindicaljau.com.br. Acesso em: 07 fev. 2011.

SLACK, N.; CHAMBERS, S.; JOHNSTON, R. Administração da Produção. Editora Atlas, 2009.

SUZIGAN, W.; FURTADO, J.; GARCIA, R.; SAMPAIO, S. E. K. (2003). Coeficientes de Gini locacionais - GL: aplicação à indústria de calçados do Estado de São Paulo. Belo Horizonte: Nova Economia, v. 13, n. $2,2003$.

WOMACK, J. P.; JONES, D. T.; ROOS, D. A máquina que mudou o mundo. Nova ed. rev. e atual. Rio de Janeiro: Elsevier, 2004.

YOSHINO, R. T. Proposta de um sistema de produção enxuta para o segmento calçadista. 315 f. Tese (Doutorado)

- Escola de Engenharia de São Carlos, Universidade de São Paulo, São Carlos, 2008.

YIN, R. K. Estudo de caso: planejamento e métodos. São Paulo: Artmed Editora S.A, 212 p., 2005.

\section{Dados dos autores:}

\section{Nome completo: Célio Favoni}

Filiação institucional: Faculdade de Tecnologia de Jahu - Fatec Jahu

Departamento: Produção Industrial

Função ou cargo ocupado: Professor

Endereço completo para correspondência (bairro, cidade, estado, país e CEP): Rua Frei Galvão, s/n,

Jardim Pedro Ometto, Jaú, SP, CEP: 17212-650

Telefones para contato: (14) 3622-8280 
e-mail: favoni@hotmail.com

Nome completo: Catarina Barbosa Caretta

Filiação institucional: Escola de Engenharia de São Carlos - EESC/USP

Departamento: Programa de Pós Graduação em Engenharia da Produção

Função ou cargo ocupado:

Endereço completo para correspondência (bairro, cidade, estado, país e CEP):

Telefones para contato:

e-mail: catarinacaretta@sc.usp.br

Nome completo: Marcos Antônio Bonifácio

Filiação institucional: Faculdade de Tecnologia de Jahu - Fatec Jahu

Departamento: Produção Industrial

Função ou cargo ocupado: Coordenador de Curso

Endereço completo para correspondência (bairro, cidade, estado, país e CEP): Rua Frei Galvão, s/n,

Jardim Pedro Ometto, Jaú, SP, CEP: 17212-650

Telefones para contato: (14) 3622-8280

e-mail: calcado@fatecjahu.edu.br

Nome completo: André Luiz Orselli

Filiação institucional: Faculdade de Tecnologia de Jahu - Fatec Jahu

Departamento: Produção Industrial

Função ou cargo ocupado: Discente

Endereço completo para correspondência (bairro, cidade, estado, país e CEP): Rua Frei Galvão, s/n, Jardim Pedro Ometto, Jaú, SP, CEP: 17212-650

Telefones para contato: (14) 3622-8280

e-mail: andre_orselli@hotmail.com

\section{Enviado em: 23/11/2013}

Aprovado em: 27/06/2013 